\title{
IMAGENS, PERCEPÇÕES E SIGNIFICADOS DO CORPO NAS CLASSES POPULARES
}

\author{
Marília Salles Falci Medeiros*
}

As feias que me desculpem, mas a beleza é fundamental! Vinícius de Moraes

Este trabalho é resultado de uma pesquisa mais ampla que foi realizada no Setor de Cirurgias Reparadoras e Estética, obra social sobre a responsabilidade do doutor Ivo Pitanguy na Santa Casa de Misericórdia, situada na cidade do Rio de Janeiro. A pesquisa tem como objetivo refletir sobre a representação da imagem e os significados que as classes populares fazem do corpo e da beleza. Aparentemente, é até incompatível refletir sobre um objeto que é característico das classes médias e altas. Pensar a beleza e procurar o cuidado do corpo não é típico apenas das mulheres de classes abastadas da sociedade brasileira.

A estética da beleza já é, no Brasil, um padrão nacional que passa por todas as classes, idades e, agora, também genêros. A beleza é uma indústria que pretende ampliar seus negócios vendendo a mercadoria estética para todos aqueles que podem comprar. Nossa intenção neste texto é procurar verificar como algumas histórias individuais podem nos transmitir significados que são reveladores de estilos de vida, dos modos de ser, expressões do padrão de gosto dos grupos populares. Escolhemos o corpo devido à possibilidade de sua mistificação. Para o observador comum, "pobre não pensa na beleza, não pode pensar na estética corporal".

Nesta pesquisa quisemos mostrar o contrário. Há um sentimento de igualação, necessidade de afirmação social em todas as classes, que passa pela necessidade de identificação com os valores

\footnotetext{
Professora do Departamento de Sociologia da Universidade Federal Fluminense (UFF).
}

Artigo recebido em 30 ago. 2004; aprovado em 28 set. 2004. 
estandardizados na sociedade dominante. A busca da beleza é mais uma expressão da identidade do povo brasileiro e, como disse Roberto da Matta, é mais uma característica típica do povo e que "faz o Brasil ser Brasil". Nossa hipótese é que as classes populares não estão fora deste sentimento estético geral e, tal como as outras camadas da sociedade, têm anseios pela aquisição da beleza. Assim, para que a investigação pudesse melhor refletir a relação imagem e corpo, torna-se importante refletir sobre o lugar que ocupa a beleza na sociedade brasileira, qual o seu papel e significado social.

\section{O Brasil e o culto à beleza}

O Brasil é também conhecido internacionalmente pelos seus estereótipos de culto à beleza. Há aqui o que se pode chamar de cultura do corpo. Contribui muito para esse cenário a divulgação midiática das cirurgias plásticas, a exportação de modelos para as passarelas mundiais, as inúmeras academias de ginástica, as exportações de biquínis ousados e as músicas e danças que são divulgadas em todo mundo exibindo canções sensuais acompanhadas de danças, apresentando a idéia de uma cultura que denota sensualidade. Estamos dentro de uma cultura narcisista, envaidecida de si mesmo e que leva a vaidade e o culto do corpo ao extremo? Podemos responder a essas questões com números, como na reportagem feita pelo jornalista William Waak $^{1}$ em uma das emissoras de televisão de maior audiência do país, que divulgou dados sobre uma pesquisa recente realizada pela Universidade de São Paulo sobre imagem e aparência no Brasil:

$86 \%$ das mulheres e $76 \%$ dos homens brasileiros preocupam-se em melhorar sua aparência. Além disso, $62 \%$ das mulheres gostariam de parecer mais jovens, e 56\% homens, também. Só 30\% das mulheres brasileiras disseram gostar das próprias rugas; entre os homens, $41 \%$ têm a mesma opinião.

Não temos dúvidas que estamos diante de uma cultura onde o corpo tem uma dimensão importante para a felicidade das pessoas e, dificilmente, no Brasil, o desgaste do corpo trazido pela velhice é algo natural, que não se vive sem sofrimento: 
No Brasil é difícil da gente se assumir do jeito que a gente é. É difícil valorizar as rugas do rosto, E se contentar somente com a idéia de que elas são resultados da história dos indivíduos e portanto delas devemos nos orgulhar. (Ventura, 2003)

Ao analisar os resultados das pesquisas divulgadas recentemente na mídia, constatamos que, quando se fala de beleza e aparência, existe entre os brasileiros um componente próprio, particular, que nos destaca muito nas comparações que se faz com outros povos e países. Para confirmar esta hipótese de que existe no Brasil uma forte preocupação com a aparência e que esta questão se tornou uma mania nacional, os dados abaixo podem servir de suporte:

$60 \%$ dos brasileiros acham fundamental a aparência física. Na média de outros países, nem $25 \%$ das pessoas dão tanta importância à aparência. $^{2}$

O mais surpreendente destas pesquisas é que nem a perfeição agrada: $100 \%$ das supermodelos, de grandes agências estão insatisfeitas com o que Deus generosamente lhes deu (Waak).

Mas, como explicar nossa preocupação excessiva com o corpo sem pensar nos custos da beleza? Se pensarmos sobre os dados, o Brasil virou o sexto maior mercado para produtos de beleza, embora nossa economia seja apenas a $11^{\text {a }}$ do ranking internacional. O diretor de marketing de uma grande empresa de cosméticos no Brasil explica:

o mercado no Brasil tem crescido sempre a taxas bem maiores que o PIB (Produto Interno Bruto), e mesmo quando o PIB apresenta retração, o mercado de cosméticos apresenta crescimento. Nos últimos anos, a soma das riquezas que o Brasil produziu, o PIB, cresceu em 7,5\%, mas as indústrias e serviços que ganham dinheiro com a nossa vontade de ficarmos mais bonitos cresceu $47 \%$. (Waak)

Como muito bem expressou um jornalista William Waak, ao comentar sobre a pesquisa da Universidade de São Paulo, citada acima, não é só no espelho que se pode examinar a vaidade brasileira, isto quer dizer que ela pode ser vista também em números. 
Se olharmos para o quadro das cirurgias plásticas, a pesquisa citada aponta, que o Brasil só perde para os Estados Unidos, que tem quase 100 milhões a mais de habitantes. Assim, aqui são feitas 350 mil cirurgias por ano, uma a cada três minutos, e a metade delas para fins estéticos. Somos também o segundo país do mundo na aplicação da toxina botulímica, um método para evitar as rugas e deixar a pele do rosto parecendo mais jovem. E apenas num dos salões de cabeleireiro mais procurados de São Paulo, 10 mil pessoas mudam a cor dos cabelos por ano. Os preços, aponta a pesquisa, são dos mais caros (Waak).

Não há dúvida que os números refletem a importância da beleza em nosso país. Não se pode esquecer que a indústria da beleza não tem só a dimensão do consumo. A expressão do jornalista explica bem o conteúdo de nossa indústria: "graças à nossa vontade de ficar bonito", criamos um espaço econômico com um grandioso mercado de trabalho que contempla todas as classes sociais, desde os médicos cirurgiões plásticos, aos esteticistas mais qualificados profissionalmente, até as vendedoras ambulantes ou a domicílio na venda através de catálogos, oferecendo produtos de beleza. É o que aponta a pesquisa:

Existe um verdadeiro exército de dedicação a nos oferecer produtos de beleza: a maior fabricante de cosméticos no Brasil tem 800 mil vendedores, quase o dobro do número de integrantes das Forças Armadas brasileiras. (Waak)

Estamos diante de dados que nos permitem afirmar o forte poder simbólico da beleza em nosso país. Podemos dizer que a preocupação com a imagem, o cuidado com o corpo é uma preocupação que passa por todas as classes sociais. Para ficar bonito, um valor universal no país, se impõe enormes sacrifícios e esforços. A pergunta que os jornalistas se fazem, "será que exageramos na importância que damos à beleza, estamos indo longe demais na preocupação com a imagem?" Pretendemos responder essas perguntas procurando relacioná-las com o processo de construção identitária de um grupo que se submeteu a um processo de cirurgia plástica na cidade do Rio de Janeiro. 


\section{O corpo como uma fábrica de sonhos}

Na introdução do livro Que Corpo é Esse?, Villaça, Góes e Kososvski $(1999$, p. 9) chamam a atenção sobre a prática universal da transformação do corpo, mostrando que esta prática não é um comportamento social recente:

Transformar ou alterar o corpo é um hábito comum a várias culturas, nos mais diversos locais do planeta. Na maior parte das vezes, esta prática tem relação com o padrão estético vigente em determinado grupo social. São casos exemplares a redução dos pés das mulheres chinesas até o princípio do século XX, o aumento dos lábios e a perfuração do nariz e das orelhas entre as tribos indígenas brasileiras; o alongamento do pescoço com anéis de metal, entre as tribos asiáticas; a criação de quelóides faciais, entre as tribos africanas, e tantas outras formas de interferência (alteração) corporal.

Os autores querem enfatizar que, na sociedade contemporânea, assistimos a uma "exacerbação desta construção corporal onde o dado natural sofre desafios".

Podemos dizer então, que as sociedades contemporâneas não se livraram do fetichismo das mercadorias, que pressupõe a fragilização do sujeito e a valorização das coisas. Permanece a antiga, e nem por isso menos importante, teoria do fetichismo da mercadoria que Marx (1983) analisou ao tratar sobre as relações sociais no capitalismo, constatando que as relações entre os homens são invertidas e tomam a forma de coisa, havendo a "personificação das coisas e a coisificação das pessoas”.

Mesmo no que se convencionou chamar de pós-modernidade ainda permanece a fragilização do indivíduo e a valorização das coisas, o que permitiu a Freud falar sobre a generalização de uma cultura narcísica, que tem no corpo uma de suas mais modernas expressões de poder, pois está permitindo aos homens não só sua transformação, mas também um maior controle e avanços pela pesquisa genética. Villaça, Góes e Kososvski (1999, p. 37) apontam o crescimento do fenômeno contemporâneo que se refere ao excessivo cuidado com o corpo: 
(...) multiplicação de academias, das revistas, dos spas, dos centros estéticos, das clínicas de embelezamento, nos tratamentos fisioterápicos, técnicas de ginásticas, onde a tônica é o imperativo, o que se percebe nas chamadas: "emagrecer", "controle a boca”, "jogo pesado contra a celulite e a flacidez", etc.

O que está em jogo é a imagem que se faz do corpo e as novas buscas de sentido que, através do capitalismo contemporâneo, são facilitadas pelo surgimento das novas tecnologias. Estas vão permitir aos indivíduos maior poder para alterarem suas imagens pela intervenção no corpo. O poder simbólico do mito da beleza e o culto narcisista retomam na pós-modernidade novos significados. Como observou o sociólogo polonês Zygmunt Bauman (1997), “a marca da pós-modernidade é a vontade de liberdade".

Tendo em vista o surgimento das grandes inovações tecnológicas, estas tornaram-se o paradigma deste século que se inicia. Com elas, um novo poder simbólico se expressa também na fragmentação do sujeito, que se constrói e se desconstrói, chegando Jean Baudrillard (1990, p. 27) a mencionar a morte de sentido, se referindo ao corpo sexuado, às intervenções no corpo, à transformação sexual, à liberdade que hoje os homens têm de transformar o seu corpo e mudar o seu significado.

Nossa intenção não é encaminhar nossas reflexões pelas análises da contemporaneidade como construção e desconstrução de novas estruturas simbólicas. Pretendemos fixar nossa atenção no ator social, nas suas percepções e procurar entender qual o lugar que ocupa seu corpo e sua imagem na constituição de sua identidade social. Para tanto, deixaremos as indagações sobre as estruturas ideológicas contemporâneas, pensadas quase sempre ao nível macrossociológico das relações culturais e políticas, inseridas no contexto global das novas determinações econômicas. Optamos por outro caminho, que tem uma linguagem mais profunda a ser investigada e, por isso, talvez mais difícil de ser percebida, por ser, às vezes, disfarçada e escondida, pois está inserida nas ações subjetivas dos indivíduos e determinam fortemente suas práticas sociais. 
Essa linguagem nos faz penetrar na esfera das representações, dos valores e atitudes dos atores que, embora nos remeta a um espaço escorregadio e impreciso, é possível decifrar seus códigos, pois eles são fundamentais para compreendermos os determinantes da ação social. Saber o significado que os indivíduos fazem de si, do seu corpo e o poder de sua imagem é parte do processo de construção de sua identidade social. Este é um processo que os indivíduos não podem fazer sozinhos, mas são reflexos e refletem as estruturas da sociedade, confrontando com os efeitos das forças sociais sofridos no interior dos indivíduos.

A nosso ver, as indagações sobre as representações que os indivíduos fazem do seu corpo e os significados que eles dão para o processo de sua construção ou reconstrução estética, podem ser compreendidas através de dois processos metodológicos, ou duas linguagens. A primeira compreende as discussões de ordem estrutural, as análises no nível das macroestruturas que inserem a beleza e o corpo no mundo da produção e na teia das relações econômicas e de consumo. Aqui, as abordagens teóricas que procuram relacionar o corpo em um sentido, mais totalizante, enfatizam os processo sociais macro como uma forma de expressão das ideologias mais formalizadas da sociedade,

A segunda abordagem enfatiza o indivíduo que busca a valorização de si para poder se impor ao outro, e segue uma linguagem mais profunda, porque vem do interior dos indivíduos e nos remete aos fracassos e vitórias, fazendo-nos penetrar num mundo mais simbólico, mais difuso escorregadio e impreciso. Mas não se pode dizer que a investigação que procura salientar os aspectos mais subjetivos dos indivíduos nas representações sobre o corpo, não nos traga resultados tão concretos e determinantes que explicam as dimensões macro da sociedade.

A primeira abordagem, mais formalizada, reflete as grandes estruturas da sociedade, nos remete ao tempo, à diacronia. A segunda abordagem nos leva a entender justamente os efeitos dessas estruturas sobre os atores, no tempo sincrônico. Aqui, perceberemos o universo 
da relação entre as regras, os valores e as resposta dos atores às estruturas da sociedade. Acontece que todo comportamento social, seja ele subjetivo ou não, é sempre o resultado dessas duas linguagens, isto é, a macro e a micro ação social são duas faces de uma mesma moeda: é neste processo dinâmico que se estruturam as regras que normatizam o grupo e que constroem as identidades individuais. Já é um bom ponto de partida, na análise, separar o geral do particular, distinguindo o que é do sujeito e o que é da estrutura. Dito de outra maneira, deve-se, portanto, indagar como o corpo pode ser visto como mais um dos veículos para que um indivíduo possa realizar sua identidade social.

\section{O objeto de investigação}

Nosso objetivo é descrever e analisar as percepções de um grupo constituído por dois homens, sete mulheres e duas meninas, sobre suas experiências com a cirurgia plástica. Nossa intenção foi compreender como esses indivíduos explicavam o significado que a cirurgia plástica teve em suas vidas, na medida em que se submeteram a uma intervenção no corpo com o objetivo de corrigir ou reparar aquilo que representavam como problemas. Isto quer dizer que nos predispomos a interpretar os microprocessos individuais que possibilitaram a elaboração de um significado objetivo que permitiu aos pacientes chegarem a uma intervenção cirúrgica. Sabemos que as representações sobre cirurgia quase sempre são marcadas por algo que se aproxima de dor, doença, riscos de morte e outros sentimentos. Nossas indagações situavam-se em dois sentidos e dois momentos:

1) quais as principais motivações das pessoas que as levaram a se submeter a uma cirurgia plástica.

2) como essas pessoas viviam a mudança e a experiência de uma nova imagem.

Assim, nossa intenção era compreender a vivência da tradicional representação do antes e o depois da cirurgia estética, e 
ver como era vivido e como era representada pelos indivíduos, na nova topografia do corpo, a nova imagem.

As entrevistas foram realizadas fundamentalmente nos espaços da Santa Casa de Misericórdia do Rio de Janeiro durante os meses de junho e julho. Nesse hospital está localizada uma obra social e uma escola de prós-graduação em cirurgia estética do doutor Ivo Pitanguy. Isto explica a composição social dos entrevistados, que são de famílias humildes, oriundas da periferia do Rio de Janeiro, ou ainda pessoas do estratos médios da sociedade. Essas são engenheiras, professoras, desenhistas industriais, ou esposas de profissionais liberais que podem pagar algum valor pela cirurgia estética. É importante observar que o preço cobrado a esses pacientes é sempre muito inferior ao mercado de clínicas estéticas da cidade do Rio de Janeiro. A Santa Casa de Misericórdia, além de ser um espaço hospitalar, acolhe também uma escola onde realiza práticas de estudos e pesquisas da equipe médica referida acima. Nesse sentido, há também o desenvolvimento de um trabalho social inteiramente gratuito de cirurgias reparadoras para os pacientes pobres ou situados entre aqueles classificados de baixa renda. Embora exista um riquíssimo trabalho social realizado através das cirurgias estéticas, não se pode omitir que esses pacientes também são um grande laboratório de aprendizagem para a equipe de cirurgia. $\mathrm{O}$ grupo de cirurgia plástica da Santa Casa de Misericórdia ajuda e também aprende muito com as cirurgias dos estratos pobres. É importante informar que o doutor Pitanguy possui também uma famosa clínica na Rua Dona Mariana, situada num elegante bairro da cidade do Rio de Janeiro, local onde são atendidos os ricos e famosos, pacientes poderosos nacionais e internacionais.

\section{O problema da pesquisa e o grupo analisado}

A Santa Casa de Misericórdia atende diariamente uma multiplicidade de pacientes interessado nas cirurgias plásticas com os mais variados objetivos. É importante observar que os pacientes se compõem heterogeneamente como categorias sociais distintas, 
como idades, cores e sexos diferentes. Encontramos crianças, quase sempre acompanhadas de suas mães, ou adolescentes sozinhos, freqüentando a clínica há anos, na busca de reparação de deficiências congênitas. Encontramos mulheres do povo, trabalhadoras sentadas no banco de espera, em busca de uma nova imagem do corpo. No Brasil, a beleza já deixou de ser coisa de mulher, o homem brasileiro já adquiriu também esta aspiração e, nos bancos de espera, encontramos também alguns homens. As idades dos homens e mulheres variam muito, como também variam as classes sociais. Os grupos de elite da sociedade, as altas classes médias se dirigem diretamente ao consultório do famoso doutor Pitanguy. Fixamos nossa pesquisa somente na Santa Casa de Misericórdia, pois o direito à beleza, graças ao doutor Pitanguy chegou também para as classes menos privilegiadas da sociedade. Como muito bem expressou a secretária do programa:

Cirurgia plástica não é mais só para milionário, os pobres também podem vir, só que vão ter que esperar numa fila, mas um dia serão chamados. Aqui, beleza pode não ter preço.

Para recortar a heterogeneidade do universo, dividimos os entrevistados em dois grupos: os pacientes de cirurgias reparadoras e os pacientes das cirurgias plásticas.

Há uma grande diferença não só no procedimento médico como também até na legislação referente a esses dois tipos de cirurgia. Há, sobretudo, diferenças marcantes também nas representações e nas expectativas dos pacientes nesses dois procedimentos cirúrgicos.

A cirurgia reparadora é caracterizada por uma ou várias intervenção, que têm como objetivo a reconstituição de algum órgão do corpo, seja ele resultado de deformações congênitas ou adquirido durante a vida. Acreditamos que esta cirurgia está mais ligada à relação do indivíduo com a saúde e a doença. Entre os casos de deformação congênita, fizemos cinco entrevistas:

- Duas meninas de nove e 13 anos, de classe média baixa, que estão há longo tempo esperando reconstituir uma orelha, pois nasceram com esta deficiência. Nessas mesmas 
condições, entrevistamos também um jovem de 19 anos, que já estava em fase final de correção. É importante observar que, nestes casos, o paciente passa por diversas cirurgias, dada a sutileza que é a reconstituição do órgão, e leva vários anos freqüentando a Santa Casa de Misericórdia.

- Uma mulher de 39 anos que tinha uma doença congênita chamada fibromatose; solteira, de classe média baixa, embora seja pedagoga.

- Um rapaz de 34 anos, desenhista industrial (designer), exmodelo fotográfico, classe média; adquiriu um câncer de pele na ponta do nariz, que mudou sua vida profissional e sua identidade social.

A cirurgia estética é caracterizada por uma intervenção que tem como objetivo corrigir as marcas do tempo. Visa claramente a busca da beleza, através do resgate no corpo de perdas ou marcas que incomodam. Nesta categoria entrevistamos:

- Uma engenheira, de 35 anos, cujas mamas cresceram muito após a maternidade; classe média.

- Uma senhora do povo, com mais de 50 anos, doméstica, que fez um lifting de rosto.

- Uma senhora de mais de 60 anos que fez uma cirurgia de pálpebras, classe média, esposa de médico.

- Uma senhora argentina, 35 anos, classe média, cirurgia de abdome.

Entrevistamos fora da Santa Casa:

- Uma professora universitária, 42 anos, classe média, fez uma cirurgia de abdômen e busto conjuntamente e procurou o grupo do doutor Pitanguy para corrigir os erros médicos ocorridos em sua cirurgia.

- Uma secretária. 
Nos nove casos entrevistados, procuramos saber como estes indivíduos representavam o processo cirúrgico a que haviam se submetido e como se sentiam antes e depois da intervenção.

\section{A construção do conceito de identidade}

Acreditamos que a teoria sobre a construção do processo de identidade possa nos ajudar a interpretar e refletir sobre as percepções que o grupo observado tem sobre os efeitos de uma cirurgia estética. Isto porque acreditamos que a identidade é própria da constituição do sujeito. Ela trás o desejo de existir, de ser reconhecido e a necessidade de identificação com o outro. Mas o que é identidade e como podemos defini-la?

O conceito de identidade aparece sempre como um conceito global, sempre impregnado de acepções muito diferentes. Tendo sido originado na psicologia, o conceito entrou recentemente no vocabulário das outras ciências, em particular na sociologia, por isso, não é tarefa fácil reconstruir o conceito sem correr o risco de empobrecê-lo.

Será necessário retomar o conceito de identidade social e procurar operacionalizá-lo para compreendermos os significados simbólicos que estimulam os indivíduos na busca da transformação do corpo.

Segundo Sylvia Ostrowetsky, a identidade é um sentimento que surge da necessidade da construção do sujeito, é algo simbólico que vem de fora, vem da sociedade e produz no indivíduo a necessidade de se identificar. Para a autora, a construção do processo identitário do indivíduo, em contato com a realidade social, passa obrigatoriamente por dois eixos: o eixo da similitude e o eixo da diferença.

O eixo da similitude é o processo que liga o indivíduo ao sentimento de igualação. O indivíduo sente a necessidade de ser igual ao outro. Esta percepção, que une duas coisas parecidas, produz uma sensação no indivíduo de se sentir igual a todos; é um sentimento que tem a característica fusional. 
O eixo da diferença é um segundo movimento que o indivíduo faz ainda pela comparatividade e, ao contrário da igualação, sente a necessidade de ser diferente, ter uma identidade. Este movimento produz a consciência do sujeito, sobre sua singularidade sua diferença. O processo identitário é definido por Sylvia Ostrowetsky (1990) como uma dialética entre estes dois espaços, interior e exterior. Neste pensamento, a identidade é vista como um processo dinâmico em que o indivíduo se constrói sempre em relação ao outro e está condenado a se constituir entre o singular e o plural.

Claude Dubar tenta operacionalizar este sentimento simbólico que caracteriza o sentimento de identidade e vai procurar pensar o conceito na sua prática empírica:

A identidade é constituída de duas faces, aparentemente contraditórias, mas que em lugar de se excluírem, se constroem e se integram mutuamente. Assim, a identidade tem uma face objetiva e outra subjetiva, que se relacionam e se integram.

Nossa intenção neste estudo é procurar entender como se articulam o processo objetivo e subjetivo, que pode influenciar os pacientes a construírem um significado próprio, particular, que justifique a busca da cirurgia estética.

As percepções sociais, que se realizam no eixo subjetivo das relações sociais, situam-se no campo simbólico e expressam diferentes formas de perceber, de olhar, de descrever, de conceituar e valorar as experiências sociais do indivíduo em relação à imagem que o sujeito faz de si e de seu corpo. Estas percepções estão ligadas praticamente às experiências do indivíduo e às suas relações originárias, com a família. Já as percepções objetivas do indivíduo estão ligadas à confrontação que o indivíduo faz com as outras instituições da sociedade, como a escola e o trabalho.

Analisando o conceito de identidade social, Claude Dubar procurou relacioná-lo ao processo de socialização. É através da socialização, que se pode entender a formação das identidades. Há inicialmente um processo de aprendizagem e, depois, de mudança, portanto uma dupla transação dos sentimentos dos indivíduos para 
que possam se identificar. Claude Dubar definiu esse processo como uma transação subjetiva e uma transação objetiva do indivíduo com o mundo social.

Pierre Tap (1979) vai explicar melhor esses dois processos. O processo de construção identitária passa por dois movimentos: a "identificação", processo pelo qual o indivíduo se integra dentro de um conjunto mais vasto ao qual ele tende a se fundir; e a "identização", processo pelo qual o indivíduo tende a se diferenciar, a tornar-se autônomo, a entrar num movimento de totalidade e se afirmar pela separação.

Podemos dizer que esses dois processos de construção identitária verifica-se naqueles que procuram interferir no corpo na busca de uma imagem estética idealizada. A cirurgia estética pode atuar naqueles que, sentindo-se portadores de uma marca depreciadora, um defeito no corpo, procuram a reparação para se tornarem indivíduos iguais aos outros. Este movimento de identificação é caracterizado pela busca de similitude e pode ser encontrado nos entrevistados que se classificam como pacientes de uma cirurgia reparadora. Como observou Goffman (1985), ser portador de uma anomalia física interfere na imagem que o indivíduo faz de si mesmo e interfere nas relações sociais realizadas em público. A cirurgia plástica tem contribuído muito para a realização deste desejo de, pelo menos, ser igual aos outros.

O nariz não se pode tampar, camuflar, cobrir. Nariz é nariz, todo mundo tem, e eu também tenho que recuperar o meu, senão .... quem é que vai agüentar me olhar? Nem eu mesmo me agüento sem ele. (Desenhista industrial, 30 anos)

O movimento de similitude é o mecanismo que mais se aproxima do desejo de normalidade, de uma representação de beleza e saúde. Por outro lado, a identidade se afirma também pela diferença. Este segundo processo é exercitado por aqueles que ultrapassam o sentimento de semelhança, de igualdade em relação ao outro e propõem impor-se agora pela originalidade de sua aparência, por um ideal de beleza pessoal. O indivíduo não quer ser apenas igual aos 
outros, mas quer ser também original, quer ser diferente. Este mecanismo pode ser compreendido através de uma entrevistada quando diz:

O problema é não ser só bonito; o problema é não ser comum. Minha mãe cansou de dizer que o peito da mulher é para isso mesmo, amamentar, todas as mulheres que deram de mamar são assim mesmo, terão o peito caído. Parece até que eles crescem mais depois da maternidade e a gente também engorda. Mas eu não quis ficar assim, eu posso ser mãe sem ter as mamas feias. Eu sofri muito tempo sentindo a minha decadência. (Engenheira, 35 anos )

Eu me sentia muito mal com todas aquelas rugas no rosto, me escondia dos outros, não me olhava. Depois a gente via a televisão, as mulheres, artistas tão bonitas, eu sofria muito. (Empregada doméstica, 60 anos).

Estas declarações enfatizam que a identidade é um sentimento, que não pode ser apreendida diretamente, mas somente pelas representações que o indivíduo faz de si em relação aos outros. A identidade permite observar que há no indivíduo um espaço interior e um olhar exterior. Há no jogo diferencial das comparações um importante mecanismo para o indivíduo se qualificar, se denominar, se identificar em relação ao outro. Assim, podemos verificar como este sentimento passa pela representação do corpo. Nas comparações aparece uma nova linguagem, que pode ser expressa pelas diversas intervenções onde se verificam os efeitos reais na transformação estética.

O processo de construção identitária não se faz sozinho. Existe a necessidade do reconhecimento de si para os indivíduos poderem se impor ao outro, isto é, ser reconhecido pelo outro. Neste sentido, primeiramente proporemos observar como os indivíduos são reconhecidos pela família. É aqui que se constrói a imagem básica da criança, para depois se confrontar com os outros da sociedade. Assim, neste estudo procuramos construir as variáveis de nossa observação, que ficarão entre os dois eixos de percepção: as transações objetivas e subjetivas que o sujeito faz com o seu próprio 
corpo, em busca do reconhecimento de si e perante a necessidade de ser reconhecido.

\section{O significado pessoal das cirurgias estéticas: uma justificativa possível}

O significado das cirurgias estéticas deve ser compreendido dentro de um processo de construção identitária, no qual os indivíduos são impulsionados a trabalhar sua subjetividade, que se revela através do corpo.

Nossa hipótese é que a cirurgia estética ocupa um lugar privilegiado no processo de reconhecimento dos indivíduos, pois ela pode ser um valioso instrumento de imposição dos indivíduos em uma sociedade que concebe a beleza como um valor fundamental. Acreditamos que a tão intensa busca pela beleza do corpo no Brasil pode também ser explicada pela necessidade de o indivíduo buscar estratégias para conseguir interações positivas numa sociedade de grandes desigualdades sociais. Interessa-nos, portanto descrever as percepções subjetivas e objetivas do sujeito sobre seu corpo, organizando o processo de observação através das seguintes variáveis a serem reconstruídas:

1) As transações subjetivas do indivíduo em relação ao corpo (o antes da cirurgia):

- a imagem que o sujeito faz de seu corpo e sua deficiência;

- a imagem que a família fez de sua deficiência;

- o significado ou justificativa para a cirurgia.

2) As transações objetivas, isto é, o mundo vivido pelo paciente:

Descrever as experiências vividas pelo sujeito com sua imagem. Aqui pretendemos entender as interações positivas e negativas do sujeito na escola, no trabalho e em outros espaços públicos. 
3) O reconhecimento de si (o depois da cirurgia):

Entender como o indivíduo se sentiu com a nova topografia do corpo, depois da cirurgia (Dubar, p. 259). ${ }^{3}$

\section{O significado da cirurgia plástica (o antes)}

Há uma clara diferença entre os processos simbólicos que são construídos pelos pacientes da cirurgia reparadora e aqueles submetidos à cirurgia estética. Por esta razão analisaremos, primeiramente, as percepções dos pacientes submetidos à reparação de uma deformidade.

\section{As transações objetivas}

Na cirurgia reparadora, o corpo deverá ser reconstruído do ponto de vista objetivo para o paciente "curar" uma doença. A deformação às vezes é tratada como doença.

O exército não aceitou a minha doença. (Rapaz que nasceu sem a orelha esquerda)

Há razões objetivas que levam os indivíduos portadores de uma deformidade a perderem o próprio emprego:

Com uma pinta negra bem na ponta do meu nariz, é impossível exercer minha profissão de modelo. Quando apareceu, eu pensei que era uma pinta, uma queimadura de sol. No início dava para disfarçar. Mas isso foi muito no início, porque logo ela começou a crescer e, depois, a sangrar. Sem saber o que era, logo perdi o emprego. Ficava inseguro, disfarçando. (Desenhista industrial, ex-modelo, 34 anos)

Há também o caso daqueles que não conseguem nem sequer realizar um ideal, pois a sociedade ainda não integra o deficiente, como podemos ver no discurso de um adolescente em processo de reconstituição da orelha esquerda:

Eu sempre sonhei em ser militar. Esperava entrar no exército para servir e depois ficar lá para fazer uma carreira. Não pude servir, com o problema da minha orelha fui julgado incapaz. Já fiz várias cirurgias mas ainda não terminou. (Adolescente) 


\section{As transações subjetivas}

Do ponto de vista subjetivo é importante observar que há uma trajetória vivida pelos indivíduos que pode ser definidora de sua identidade. Não é o indivíduo que caracteriza sua relação com a deformidade. O sentimento de deformação é interiorizado primeiramente na família para, depois, ser vivida externamente. A deformação é vivida subjetivamente, conforme a criança experimenta sua aceitação dentro do próprio seio familiar:

Quando a menina nasceu, já com a deficiência, me perguntaram na maternidade se eu aceitaria minha filha de qualquer jeito. Ela não só não tinha a orelha direita, como também tinha a face direita completamente deformada, afundada, um horror.

As pessoas me perguntavam se eu não queria me livrar dela (a filha sem orelha) perguntavam também se eu fiz algum pecado para ela nascer assim, se não tomei algum remédio.

Por causa dela eu tive que perder o trabalho, não posso mais trabalhar fora, tive que arrumar um jeito de trabalhar em casa mesmo. Tenho que trazê-la sempre aqui (Santa Casa), quase todo dia. (Mãe de uma jovem)

Além de culpabilizar a deficiência da filha, esta senhora expressa claramente o sofrimento e o peso que é para as famílias a deformação congênita e o doloroso processo de reconstituição do órgão na cirurgia reparadora. O processo subjetivo é construído de fora para dentro e depende da concepção da família em aceitar a deformação do filho:

Todo mundo sempre pergunta pela orelha da minha filha, hoje mesmo no ônibus perguntaram. É assim, eles não nos deixam esquecer, tem sempre uma pergunta...

Do ponto de vista subjetivo, essas classificações é que vão formar as bases fundamentais do processo de identidade do indivíduo. A percepção da marca depreciadora no corpo produz no indivíduo imensos sofrimentos e segregação, até mesmo dentro da família. Primeiro sofre um processo de acusação e depois a perplexidade da descoberta da diferença: "Porque isso aconteceu comigo?" 
Há também o desejo compulsivo das pessoas quererem usar exatamente o órgão deficiente:

Ela adora brinco mas não pode usar o brinco. Depois de algumas correções, ela já quis logo usar brincos. Ela adora brincos.

Os defeitos vitais, até mesmo estruturais do corpo, se escondidos doem menos que aqueles mais visíveis. Assim, uma mãe sofre mais pela deformação da orelha da filha do que pelos problemas de coluna que podem agravar a estrutura geral do corpo. A visibilidade é que incomoda mais e impede o sujeito de realizar o processo de identificação com o outro. O sentimento inicial que é despertado refere-se à necessidade do processo de igualação, ser igual ao outro, possuir as mesmas identificações.

Agora ela já pode fazer até um rabo de cavalo. (Mãe da menina de 13 anos)

A trajetória do indivíduo para superar o sentimento de monstruosidade que a deformação lhe dá começa no momento que ele chega à Santa Casa, onde é fundamental o encontro da criança e das famílias com outras que são portadoras dos mesmos problemas. O encontro com o outro ameniza o sofrimento da família e faz nascer a esperança:

Aqui foi muito bom para nós, pois encontramos crianças portadoras dos mesmos problemas dela e até mesmo pior do que os dela.

Para que os indivíduos possam conseguir a difícil tarefa das interações em público, eles têm que construir um significado que lhes permita enfrentar o outro, mesmo como diferente.

A religião me ajudou muito a me aceitar. Ficar boa, boa mesmo eu não vou ficar, mas já está bom para mim do jeito que já está . É procurar viver o melhor possível. (Mulher com fibromatose)

$\mathrm{Na}$ cirurgia reparadora, o paciente vive um longo processo e ele não espera a reconstrução perfeita do órgão deformado. Se os médicos conseguirem atenuar a deformação, isso já é vivido pelo 
paciente como vitória. Na cirurgia estética, ao contrário, o paciente espera, com a correção, atingir a perfeição da forma:

Não agüentava mais meu corpo, vim aqui para tirar essa barriga, ela me incomodou anos, mas também eu não quero o meu corpo marcado. Não faço cirurgia para agradar ninguém. É para me sentir bem que eu fiz a cirurgia. Se ficar mal feita, não resolverá o meu problema. (Mulher argentina)

Depois de tudo que eu vivi consegui um peito melhor do que eu tinha antes. Hoje ele é pequeno, mas eu sempre tive eles grandes, eu sempre quis um peito como eu o tenho hoje. (Engenheira)

\section{A cirurgia estética}

A cirurgia estética é fundamentada num desejo de corrigir as marcas do tempo, o exagero de determinados órgãos, como as mamas ou o nariz, para o indivíduo realizar um ideal de beleza. Há aqui a construção pessoal de um desejo e de um padrão de beleza.

\section{Transações objetivas}

Do ponto de vista objetivo, a construção deste padrão vem de fora para dentro, há um padrão de beleza padronizado pela sociedade, uma moda que cobra diariamente dos indivíduos a sua realização. $\mathrm{O}$ Rio de Janeiro tem suas imagens difundidas por todo mundo, revelando um repertório de concepções sobre sua beleza natural e o modo de ser carioca. No imaginário sobre a cidade, quase sempre se confunde a beleza das praias e das montanhas com a sensualidade das cariocas. O carnaval representa a alegria do modo carioca de viver e a beleza do corpo é fundamental, sendo atualmente altamente explorada pela mídia, pelas atrizes de televisão, que se tornam os modelos e o padrão dos sonhos de beleza nacional.

Por outro lado, a própria topografia da cidade e a necessidade de desfrutar da paisagem, do sol, do prazer de viver à beira do mar, a descontração das infinitas praias da cidade levam as pessoas da cidade a se identificarem com os corpos e associá-los ao espetáculo do clima e da natureza. O Rio é uma cidade de solicitações sensuais e o 
corpo ocupa aqui um forte lugar de destaque no imaginário da cidade. A descontração, o corpo e o desejo de beleza aqui são exacerbados. Há, portanto, um estímulo aos cuidados do corpo. Os estereótipos culturais são utilizados ou acentuados por ilustradores e cartunistas de jornais de grande circulação que apresentam os contornos das montanhas cariocas como se fossem silhuetas gigantescas de corpos femininos. Trata-se de um imaginário paradoxal acentuado por uma realidade social marcada pela pobreza estampada na favelização desenfreada e na crescente violência urbana. Contudo, é necessário investigar nas histórias individuais dos entrevistados quais são os significados ou as justificativas que os levaram à cirurgia estética.

\section{Transações subjetivas}

Na relação com o corpo, o sujeito tem a sensação de "posse". Mas é freqüente encontrarmos representações simbólicas que demonstram a perda do controle do corpo, pelo envelhecimento e pela doença. Neste sentido, a identidade do indivíduo se fragmenta, na representação "do que eu era" e "do que sou hoje". Daí a necessidade da busca de resgate da juventude perdida e a necessidade dos indivíduos superarem a dualidade da representação de si e buscarem um resgate inicialmente no corpo para poderem reencontrar a si mesmos. O corpo é a fachada que se expõe e sem uma boa aparência não adianta riqueza, saber ou outra coisa qualquer. Este é o domínio simbólico e o poder que exerce a aparência para o grupo de cirurgias estéticas que estudamos. Para provarem que podem interferir no tempo e na natureza, os pacientes da Santa Casa constroem uma justificativa para superar a dolorosa experiência de uma cirurgia estética.

Assim, a intervenção resgata o domínio do corpo como se desafiasse o tempo e a lei da gravidade. Para isso, os pacientes constroem uma representação do médico, um condutor sagrado capaz de resgatar a imagem perdida, através de uma poderosa máquina do tempo, capaz não só de vencer a natureza mas também as leis da gravidade. $\mathrm{O}$ paciente o representa como um salvador, que tem as 
mãos sagradas, capaz de conduzir às coisas boas do mundo. Sagrados aqui são a beleza e o médico é capaz de construir ou reconstruí-la. É comum no Brasil as artistas de televisão afirmarem:

O meu rosto foi o Pitanguy quem o fez, ele é um cientista da beleza. (Depoimento de uma célebre atriz brasileira, 53 anos - plastificada)

A equipe da Santa Casa foi maravilhosa, trata as ricas do mesmo jeito que as pobres, se não fosse a equipe que me atendeu, eu jamais arriscaria uma cirurgia no rosto. (Depoimento de uma atriz de televisão, 56 ano - plastificada )

São várias as histórias, mas, em geral, podemos agrupá-las nas seguintes representações: sentimento de estar bem, rito de passagem, superação da insegurança nas relações afetivas.

\section{a) O sentimento de estar bem}

Hoje, quando se fala em beleza, para mim, não é só os cuidados estéticos, é procurar me sentir bem comigo mesma. Não é para eu agradar ninguém, é para eu agradar eu mesma. É eu poder me olhar no espelho, o que não fazia há muito tempo, não tem nada de luxo.

Esta entrevista mostra claramente que, hoje, ao se pensar em beleza não se pode tratá-la somente como vaidade ou cuidados estéticos. Como muito bem mostrou um médico entrevistado na pesquisa realizada pela Universidade de São Paulo, "estar bem" já faz grande parte dos objetivos de grande maioria dos pacientes da cirurgia estética:

(...) é um estar bem que vai além do corpo, atinge a alma dos indivíduos, resgata a auto-estima, produz segurança e pode contribuir para atenuar as angústias. Já vi alguns casos em que os pacientes adquirem equilíbrio e até mesmo segurança de si.

É necessário, primeiro, o sujeito estar bem em relação a si próprio para, depois, poder se sentir bem com os outros. A sondagem encomendada pela Avon afirma que se enganam aqueles que pensam que as brasileiras se arrumam só para agradar ou causar inveja às suas rivais:

A esmagadora maioria se embeleza principalmente para si própria. 
Apenas $19 \%$ das brasileiras se enfeitam para os outros.

\section{b) Um rito de passagem}

Uma cirurgia pode significar a passagem de uma etapa de vida para outra muito melhor. É o que nos disse mais uma profissional da beleza, uma enfermeira, esteticista, da Santa Casa de Misericórdia.

Não se pode subestimar o que uma cirurgia plástica pode significar, as pacientes daqui entram em outro mundo, começam a reviver hábitos que, com o tempo, elas foram obrigadas a perder. Por exemplo, poder ir a praia, usar um biquíni. Isto para elas é muito importante.

\section{c) Insegurança nas relações afetivas, o papel da família}

Grande parte das cirurgias estéticas era feita por mulheres que perderam a antiga forma do corpo e que por isso, às vezes, são cobradas pelos maridos. A perda da antiga forma ou o envelhecimento produz efeitos negativos na relação do casal.

Ele é engenheiro como eu era, mas, com a gravidez, tive que ficar em casa, minhas mamas caíram, cresceram muito e eu engordei. Vivi nesta situação mais de 10 anos. Eu era super insatisfeita, e com a cirurgia comecei a mudar. Hoje trabalho e sinto-me muito bem com meu corpo. (Engenheira, 35 anos )

Entre as entrevistadas havia algumas mulheres que só depois da cirurgia estética começaram a pensar em se relacionar com um namorado e, até mesmo, em se casar.

Tenho mais de 60 anos, agora quem sabe eu posso arrumar um marido, deixei passar o tempo, agora com a cirurgia quem sabe ainda posso arrumar um namorado, depois um marido. Eu gostaria que fosse um pastor da Igreja Universal.

Lá em casa todos diziam que eu era tão feia com estes caroços no rosto, que eu nem pensava de me casar. Agora eu sinto que isso pode acontecer. (Pedagoga, 40 anos)

Fica, pois, evidente que é na relação afetiva com o marido ou namorado que se revela claramente o processo de desvalorização de si pelos defeitos colocados no corpo. A grande importância depositada 
no corpo é mais do que uma vaidade - é, sobretudo, uma alternativa para a busca do outro, ou a atenuação da angústia e, até mesmo, a superação do sentimento de rejeição. O corpo é, portanto, o veículo das trocas sexuais e afetivas, e é objeto de um grande poder simbólico na revelação do ser. A imagem que o indivíduo faz do corpo pode facilitar ou até determinar interações positivas na relação a dois. É o que podemos analisar nas falas de duas entrevistadas:

Detestava a luz, em minhas relações amorosas jamais mostrava o meu corpo, vivia me cobrindo, me escondendo. Depois da cirurgia ao contrário, agora faço questão de mostrá-lo, com luz acesa e tudo. (Secretária)

Depois da cirurgia, comecei a me vestir melhor, deixei meu cabelo crescer um pouco, comecei a gostar de me cuidar, a minha vida mudou tanto... Aquela imagem que eu tinha antes eu quero esquecer, hoje todo mundo me cumprimenta na rua, me convida para as festas na igreja, vendo muito mais os meus produtos. (Empregada domésticavendedora de produtos Avon)

O processo de constituir-se como sujeito não se faz só pelo espírito, passa, sobretudo, pelo corpo. Não se pode negar que, no Rio de Janeiro, o corpo está muito ligado ao processo de subjetivação do sujeito, como tão bem expressou Tucherman (1999):

Certamente que se constituir como sujeito requer do indivíduo a constituição de si como objeto de cuidado; inversamente, cada cultura irá designar o que precisa ser cuidado.

\section{Conclusões}

Para a cultura brasileira, a beleza é um capital simbólico de grande poder social e o corpo é a marca desse poder social. Assim, não é só a beleza, mas o investimento que se faz na aparência, que produz interações positivas. $\mathrm{O}$ corpo pode expressar a marca de uma afirmação social e pode desencadear um processo de equilíbrio pessoal. A cirurgia estética, assim como a cirurgia reparadora, permite a construção e a reconstrução identitária, resgatando uma identidade fragmentária, marcada por algum traumatismo no corpo, comprometendo a aparência do indivíduo. 
Grande parte dos entrevistados ficou feliz com os resultados, mas nem todos conseguiram chegar ao paraíso através do bisturi do cirurgião plástico. Embora o corpo fosse o foco visado pelo sujeito, após a cirurgia sua dimensão individual não se alterou. Não era o corpo o problema, mas algo externo ao corpo ou interno ao indivíduo é que precisava mudar. A cirurgia não alterou sua insatisfação existencial. Ela inclusive provocou maior insatisfação. Iremos expor três histórias modelares.

\section{1) Glória: uma identidade vitoriosa}

Nascida na periferia do Rio de Janeiro, de origem humilde, exempregada doméstica, vivendo de uma pensão deixada por seu pai, funcionário da Rede Ferroviária Federal, chegou aos 58 anos e não conseguiu se casar. Parece que o espaço mais importante de suas interações são os cultos da igreja protestante. Conheci esta senhora sentada na sala de espera da Santa Casa de Misericórdia esperando uma consulta para fazer a última revisão de sua cirurgia: lifting completo de face.

Procurei entrevistá-la, porque soube pelas outras pacientes que seu caso foi uma grande vitória médica, pois já estava com acentuadas marcas no rosto, longas rugas na testa e pescoço, sulcos profundos entre os lábios que lhe davam uma aparência de pessoa triste e angustiada. Vi suas fotos anteriores, que ela exibiu com grande satisfação por saber que aquela fisionomia fazia parte do passado. Outro tempo que ela só queria se lembrar para repetir: "Eu venci! Tive coragem de vir aqui e o doutor Marcos me operou."

O caso desta senhora é importante, pois mostra uma cirurgia que obteve muito êxito, não só médico, mas por ela ter gostado do resultado. Conversando com ela, pude perceber que não se pode superestimar a vaidade feminina e atribuí-la a somente aquelas mulheres que têm recursos econômicos e podem desfrutar do modismo de construir o corpo. O que a levou à busca da beleza? Insatisfeita com a própria aparência, ela viveu muitos anos se 
desvalorizando, assistindo à chegada progressiva da "velhice" no corpo:

Há muito tempo eu tinha perdido minha alegria de viver, não gostava do meu rosto e vivia me escondendo. Eu via as artistas tão bonitas, porque que elas podem fazer a plástica e eu não posso? Aí, soube da Santa Casa, vim aqui e todos me atenderam muito bem, o resultado é este e não podia ficar melhor. Agora já me sinto outra pessoa, penso até em namorar, arrumar um casamento para mim.

Neste relato percebi que não se pode subestimar o que uma mudança de aparência pode fazer na vida de uma mulher, e nem sentir que há uma preocupação excessiva com a aparência. Existem mulheres que ficam tão felizes e mudam tanto depois da cirurgia, que fazem coisas que nunca conseguiram realizar ao longo de toda sua trajetória de vida.

\section{2) Márcia: uma identidade resignada}

Márcia é professora primária, nas escolas do $1^{\circ}$ e $2^{\circ}$ graus da Prefeitura do Rio de Janeiro. Originária de uma família pobre, com muito esforço conseguiu um diploma de pedagoga, em uma universidade particular, na periferia da cidade. Nasceu com fibromatose, uma doença que lhe produz inúmeros caroços no corpo, sobretudo no rosto. São caroços que, mesmo sendo retirados, acabam voltando, dando uma péssima imagem à pessoa. Márcia não podia seguir o culto do corpo, porque sua doença lhe trazia inúmeros sacrifícios e lhe impunha vários limites.

Essa situação não a impediu de procurar de alguma forma melhorar sua aparência, sua imagem estética. Sempre subestimou muito seu corpo e sofreu inúmeros dissabores. Fiquei curiosa em saber como conseguiu superar seus limites e adquirir uma profissão, morar sozinha e fazer um curso universitário. Na entrevista percebi que ela é uma pessoa de muita fé, freqüenta a igreja com muita regularidade. A fé e a religião podem ter tido um papel muito importante, sendo o seu elemento de equilíbrio para aceitar a doença: 
Sempre tive muita fé e sei que nada para Deus é impossível. A religião me ajudou muito a aceitar a minha aparência.

Márcia freqüenta a Santa Casa de Misericórdia há algunss anos e já passou por várias cirurgias na face para retirar os caroços produzidos pela fibromatose. No entanto, sua expectativa não é a forma perfeita, já se sente feliz com a atenuação de suas imperfeições.

\section{3) Wanda: uma identidade em conflito com a aparência}

Wanda tem 42 anos e é professora universitária. Divorciada há 12 anos, ela se sente vítima da cirurgia estética. Ela não fez sua cirurgia com a equipe do doutor Pitanguy na Santa Casa de Misericórdia. Ao contrário, foi até lá para fazer uma avaliação dos erros cometidos na cirurgia realizada numa clínica da cidade de São Gonçalo, na periferia do Rio de Janeiro.

Eu era uma pessoa que não tinha o corpo padrão, mas que convivia com este corpo muito bem. Hoje, depois da cirurgia, eu deixei de conviver bem com este corpo, pois este corpo deixou de ser o corpo padrão, não para a sociedade mas para mim. Eu estava muito afim de fazer a cirurgia plástica porque eu tinha um objetivo, não porque era a cirurgia plástica mas porque era a minha vida. $\mathrm{O}$ que ele me cortou foi muito mais que a pele do meu abdome, que hoje me impede de engravidar, ele cortou a minha vida. Chorava muito quando via meu corpo, quando ia tomar banho e sentia muita culpa por ter feito esta cirurgia plástica.

Para a entrevistada, a cirurgia marca uma passagem, o antes e o depois descritos de forma angustiada e profundamente revoltada por causa dos resultados de uma cirurgia dupla de mamas e abdome. Como a entrevistada justifica as transações positivas que a levaram à cirurgia plástica?

A cirurgia representou para Wanda um processo de retomada de uma fase da vida, na qual diversas experiências não foram felizes. Como militante sindical, viveu derrotas políticas, teve várias infecções geradas por crises de angústia, solidão como resultado de separações e divórcio. Um acidente de automóvel a obrigou a tomar cortisona 
por um longo tempo, o que resultou num processo progressivo de aumento de peso. Chegou a engordar mais de 10 quilos, o que, para sua altura, foi excessivo. Como já tinha naturalmente mamas grandes e desproporcionais para o corpo, com o aumento de peso estas vieram a incomodá-la, pressionando a coluna.

Mas não foi exatamente o problema das mamas que a impulsionou para fazer a plástica. Como declarou várias vezes na entrevista, a cirurgia para ela representou uma retomada de vida. Wanda foi aprovada para fazer um curso de pós-graduação em uma das melhores universidades do Brasil, na cidade de Campinas, com um orientador valorizado por ela e ganhou uma bolsa de estudos de quatro anos. A cirurgia surgiu como mais um componente para a renovação da vida. Fez um longo planejamento, seguiu dietas, emagreceu e fez economias para pagar o cirurgião. Estava confiante no profissional e controlava inclusive os riscos previsíveis que poderiam surgir, durante a cirurgia. Jamais poderia pensar que todos os seus problemas surgiriam no pós-operatório, por negligência da equipe médica. Contraiu flebite nos braços por erro do anestesista e foi vitimada por um mamilo necrosado, que comprometeu toda a estética da mama por ausência de assepsia no pós-operatório. Hoje tem dificuldade de ficar ereta, pois a cirurgia do abdômen retirou excesso de músculos, impedindo-a de engravidar.

O depois da cirurgia tem sido uma longa luta jurídica, pois ela abriu um processo contra o médico responsável. Em virtude do mal físico, moral e psíquico de que foi vítima, hoje sente-se psicologicamente impossibilitada de refazer as correções necessárias. Não só as cicatrizes visíveis, mas também as invisíveis a impedem de ser feliz e ela não se sente mais capaz de confiar em outra equipe médica. Saiu do processo cirúrgico sem encontrar o paraíso, como muitas conseguiram encontrar uma outra dimensão da vida. Traumatizada com a relação com o médico e impossibilitada de fazer a correção dos defeitos, vive e se alimenta moralmente da batalha jurídica que travou com o seu médico. Teve que estudar as leis para ela mesma fazer e escrever sua defesa.

Wanda descreve com um imenso sofrimento a negligência médica que comprometeu o seu corpo no pós-operatório: 
Descobri que muitas mulheres têm problemas em decorrência da cirurgia plástica, que elas não têm consciência de que estes problemas são falhas dos médicos. Elas são convencidas que os resultados são decorrentes do corpo delas. O meu médico disse que a cicatriz do meu abdome está assim porque minha pele escurece.

Segundo ela, os cirurgiões impõem sua opinião estética sobre o resultado final da cirurgia e algumas pacientes acabam sendo submetidas e enganadas pelo discurso médico:

Eles impõem o discurso deles às mulheres do povo. Invertem as reclamações, quando elas existem, e dizem que é a paciente que tem uma expectativa acima do normal.

Na batalha judicial travada contra o erro médico, a professora descobriu uma entidade corporativa, que fecha as explicações científicas para o leigo. Da forma como narrou sua experiência, os médicos são colocados como "máfias" da saúde, um protegendo o outro, comprando os advogados de defesa e impedindo a criação de uma jurisprudência capaz de legislar sobre os erros médicos.

Um professor da área jurídica da Universidade Federal do Rio de Janeiro explica para a entrevistada o que está por trás das aparências:

A briga em que você entrou não é contra pessoas, mas contra a criação de uma jurisprudência. Então todas as clínicas têm um "caixa 2". Compram, pagam jurados, médicos, advogados para impedirem a criação de uma jurisprudência capaz de proteger as vítimas dos erros médicos.

Aguardando o parecer da justiça, Wanda está agora conseguindo trabalhar, fazendo terapia analítica, e começa a namorar, só que nesse resgate da vida afetiva, não poderá engravidar. Termina a entrevista com a seguinte fala mostrando claramente sua identidade dividida:

Eu não sou isso que eles me fizeram ser, eu sou outro, carrego aquele corpo antigo, sem marcas sem cicatrizes, como um ideal do que perdi. 


\section{Notas}

1 Disponível em: <www.globo/jornalismo>, Matérias Especiais.

2 O cuidado das brasileiras com a aparência está quantificado numa pesquisa com 21 mil mulheres, de 24 países, concluída recentemente. A sondagem foi encomendada pela Avon, uma das maiores multinacionais na área de cosméticos, e serve para auxiliar a companhia a traçar suas estratégias nos quatro cantos do mundo. Os resultados desta pesquisa são surpreendentes e confirmam: não há mulheres tão preocupadas com a aparência quanto as brasileiras. Pesquisa divulgada pela revista Veja, número 1818, 3 de setembro de 2003.

3 O termo transação é utilizado no sentido que Claude Dubar, fundamentado nas teorias de Jean Piaget, o definiu: "O termo é usado (neste capítulo) em sentido largo, incluindo a transação com o outro dentro de um sistema de ação e a transação consigo mesmo dentro de um processo biográfico. O uso de um ter se justifica pela estrutura comum de processos relacional e biográfico.” (p. 259).

\section{Referências bibliográficas}

BAUDRILLARD, Jean. A transparência do mal. São Paulo: Papirus, 1990.

BAUMAN, Zygmunt. O mal-estar da Pós-Modernidade. Rio de Janeiro: Jorge Zahar, 1997.

DUBAR, Claude. La socialisation: construction des identites sociales et professionnelles. Paris: Armand Colin.

GOFFMAN, Irving. O estigma. Rio de Janeiro: Zahar, 1985.

MARX, Karl. O capital - I volume. São Paulo: Abril Cultural, 1983.

OSTROWETSKY Sylvia. La representation et ses doubles. Communication Information, v. 6, n. 213.

L'identité et culture. In: SEMINÁRIO DO CURSO DE DEA DE SOCIOLOGIA. Université de Picardie, Amiens, França, 1990. «Les Mots, lês Choses et le Lieu» ( Mimeogr).

TAP, Pierre. Identités colletives et changements sociaux. In: COLLOQUE INTERNATIONAL DE TOULOUSE, septembre 1979. 
TUCHERMAN, Ieda. A construção dos monstros e as raças fabulosas. In: VILLAÇA, Nízia; GÓES, Fred; KOSOSVSKI, Ester. Que corpo é esse? Rio de Janeiro: Muad, 1999.

VENTURA, Zuenir. Ruga é fundamental. $O$ Globo, Rio de Janeiro, 13 set. 2003, Caderno Opinião.

VILLAÇA, Nízia; GÓES, Fred; KOSOSVSKI, Ester. Que corpo é esse? Rio de Janeiro: Muad, 1999.

WAAK, William. Matérias especiais. Disponível em: <www.globo/ jornalismo>. 
